\title{
Time Step Issue in Unit Hydrograph for Improving Runoff Prediction in Small Catchments
}

\author{
Dyah Indriana Kusumastuti, Dwi Jokowinarno \\ Department of Civil Engineering, University of Lampung, Bandar Lampung, Indonesia \\ Email: kusumast@gmail.com
}

Received May 20, 2012; revised June 20, 2012; accepted June 28, 2012

\begin{abstract}
Unit hydrograph is a very practical tool in runoff prediction which has been used since decades ago and to date it remains useful. Unit hydrograph method is applied in Way Kuala Garuntang, an ungauged catchment in Lampung Province, Indonesia. To derive an observed unit hydrograph it requires rainfall and water level data with fine time scale which are obtained from automatic gauges. Observed unit hydrograph has an advantage that it is possible to derive it for various time steps including those with time step less than an hour. In order to get a more accurate unit hydrograph, it is necessary to derive a unit hydrograph with small time step for a small catchment such as those used in this study. The study area includes Way Kuala Garuntang and its tributaries, i.e. Way Simpur, Way Awi with areas are $60.52 \mathrm{~km}^{2}$, $3.691 \mathrm{~km}^{2}$, and $9.846 \mathrm{~km}^{2}$ respectively. The results of this study highlight the importance of time step selection on unit hydrograph, which are shown to have a significant impact on the resulting unit hydrograph's variables such as peak discharge and time to peak.
\end{abstract}

Keywords: Unit Hydrograph; Time Step; Peak Discharge; Time to Peak

\section{Introduction}

The development of hydrology model in runoff prediction is very advance, in which there are several methods that can be used in runoff prediction in ungauged basin. Especially with the existence of PUB (Prediction in Ungauged Basin) [1,2], there are several supporting tools and methods which makes prediction possible in such catchments. The choice of methods and tools are based on available data in that region. The limitation of fine data such as data from radar, leave little choice to carry out prediction in some catchments. As many other catchments in many parts of the world, Way Kuala Garuntang is an ungauged catchment. There was no runoff measurements recorded before. This increasingly grows into significant matter as floods occur more frequently in this region recently [3]. It is believed that one of the best options to do runoff prediction is by taking runoff measurements [4]. Therefore this study deals with instrumenting this ungauged catchment to gain important information and carry out necessary analysis, as well as predicting runoff using observed unit hydrograph (UH) method.

Despite its conservative method, the unit hydrograph approach to rainfall-runoff modelling remains a very useful and practical approach to deal with operational hydrological forecasting [5]. In this case UH model structure is assumed to be appropriate to represent catchment behavior by assuming two separately acting functions, i.e. the production and the transfer functions [5]. When a certain amount of rainfall reaches the ground, some will loss due to infiltration or others, and there remains a reduced part called the effective rainfall which then transformed into direct runoff. This runoff is then delayed and transferred to the outlet by various routing mechanisms. Unit hydrograph is a linear transfer function that represents those mechanisms with an assumption that the mechanisms behave similarly from event to event.

The choice of using observed unit hydrograph, because this method is capable in predicting time to peak of runoff more accurately as this method can do the computation for time step less than one hour. This obviously an advantage of using observed unit hydrograph compared to synthetic unit hydrographs (SUH) such as Nakayasu, GAMA I and Snyder and other kind of SUH which have time step of hour [6-9]. Time step becomes an issue here as the selected catchments are small catchments less than $100 \mathrm{~km}^{2}$ of area, which may need short time concentration for the flow to propagate to the outlet. Hence, this study aims to investigate the impact of time 
step selection in resulting unit hydrograph.

\section{Methodology}

\subsection{Description of Study Area}

The work took place in Way Kuala Garuntang catchment including its two sub-catchments, Way Simpur and Way Awi as presented in Figure 1). Way Simpur and Way Awi are two neighbouring sub-catchments, while those two sub-catchments are cascading to Way Kuala Garuntang catchment. The catchments located in Lampung Province, Indonesia. The area of Way Simpur, Way Awi and Way Kuala Garuntang catchments are $3.691 \mathrm{~km}^{2}$, $9.846 \mathrm{~km}^{2}$ and $60.52 \mathrm{~km}^{2}$ respectively. Three runoff measurements were carried out, two in the tributaries i.e. Way Simpur, Way Awi and one in the downstream of Way Kuala Garuntang River. There is no runoff measurements in these catchments before. In order to construct an observed unit hydrograph, several things need to be prepared. Three automatic water level recorder (AWLR) needs to be installed in those locations, one for each point. There is one tipping bucket raingauge located in Way Kuala Garuntang catchment and the rainfall data obtained from this raingauge is used to calculate the unit hydrographs for each catchment.

The topography of upstream part of the catchment is hilly and the slope is flatter toward downstream catchment. Way Simpur and Way Awi, they are neighbouring catchments but the catchment characteristic is slightly different. Way Awi catchment is highly populated where their house is located close to each other, therefore most rainfall is transformed into runoff. During intense storm event, flood comes quickly, but then releases in short period of time. The channel width varies, where the width at the location study is 8 meters. Way Simpur is also a rural catchment and highly populated. The slight difference is during intense storm event, flood comes quickly but releases slight longer period of time compared to release time in Way Awi. The channel width at the location of study in Way Simpur is 7.5 meters and in Way Kuala Garuntang the river has 9 meters width.

\subsection{Rating Curves}

Measurements of discharges and water levels at those three points were carried out during wet season October 2009-April 2010. Velocities were measured using current meter and water levels were observed using peilschaal attached on the river bank. Based on those measurements, a rating curve for each point is determined and results are presented in Figure 2. Rating curve for Way Simpur (Figure 2(a)) shows the increase of water levels resulted in lower increase of discharges compared to that for Way Awi (Figure 2(b)), which is presented by sharper slope of Way Awi's rating curve. Please note that the scales of rating curves for both Way Simpur and Way Awi are the same, but differ from those of rating curve for Way Kuala Garuntang. Rating curve for Way Kuala Garuntang (Figure 2(c)) shows the extensive range of discharges, which in the measurement for $1.2 \mathrm{~m}$ water level causes discharge of about $25 \mathrm{~m}^{3} / \mathrm{s}$.

\subsection{Effective Rainfall}

This study used a classic $\phi_{\text {index }}$ approach to determine the effective rainfalls. Although there are quite a number of approaches used to determine the effective rainfalls such

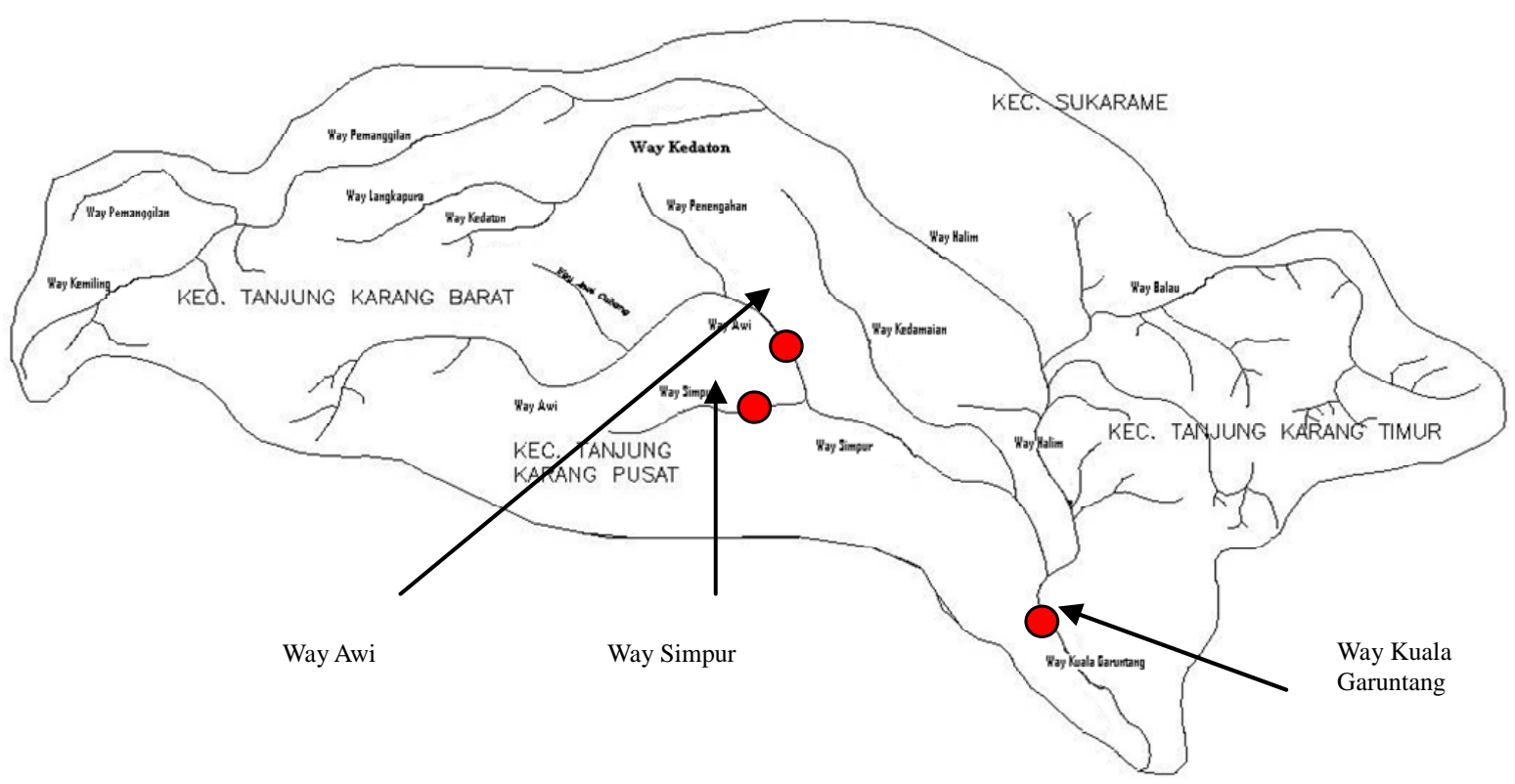

Figure 1. Way Simpur, Way Awi and Kuala Garuntang catchments and the locations of the runoff gauges. 
as Green Ampt infiltration and others, $\phi_{\text {index }}$ approach is still widely used due to its simplicity. The approach produces a series of excess rainfall (PE) or effective rainfall values from the observed gross rainfall (PG) values. The only constraint is to fit the overall so-called "stormflow" volume which is thought to have become runoff. Subsequently, the computed series of excess precipitation and the observed discharge $(Q)$ are used to calibrate the UH in a 'known input known output' context [5].

The equation used to calculate $\phi_{\text {index }}$ is shown in Equations 1 and 2, where runoff depth $\left(Q_{D R}\right)$ is a result of volume of direct runoff $\left(V_{D R}\right)$ divided by catchment area $(A)$. Thus $\phi_{\text {index }}$ is the difference between gross rainfall $(P)$ and runoff depth $\left(Q_{D R}\right)$ divided by time $(t)$. Excess precipitation or effective rainfalls are obtained as gross precipitation subtracted by $\phi_{\text {index }}$.

$$
\begin{aligned}
Q_{D R} & =\frac{V_{D R}}{A} \\
\phi_{\text {index }} & =\frac{P-Q_{D R}}{t}
\end{aligned}
$$

\section{Results and Discussions}

\subsection{Flood Events, Time Steps and $\phi_{\text {index }}$}

There are several flood events recorded during wet season 2009-2010, and the events are presented in Tables 1 to 3 for flood events selected for Way Simpur catchment (Table 1), Way Awi catchment (Table 2), and Way Kuala Garuntang catchment (Table 3). For each event, other related parameters such as rainfall depth, rainfall duration, calculated $\phi_{\text {index }}$ are also presented. Please note that the calculated $\phi_{\text {index }}$ are for three time steps, i.e. 10, 30 and 60 minutes.

It can be seen that the first recorded flood event was in December, although the start of wet season is in October. This happened because the first few rains were mostly infiltrated to fulfill soil moisture capacity. Furthermore, flood events presented in Tables 1-3 are those which can be used to develop unit hydrograph. The advantage of using observed unit hydrograph to synthetic unit hydrograph such as Nakayasu, Snyder and GAMA 1, is the possibility to develop a unit hydrograph with finer time

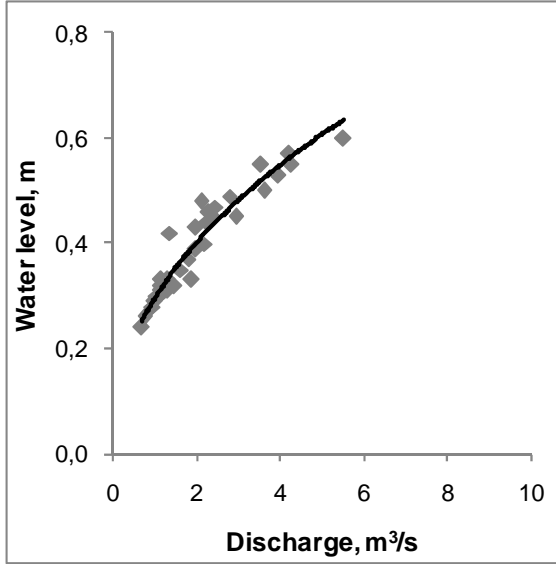

(a)

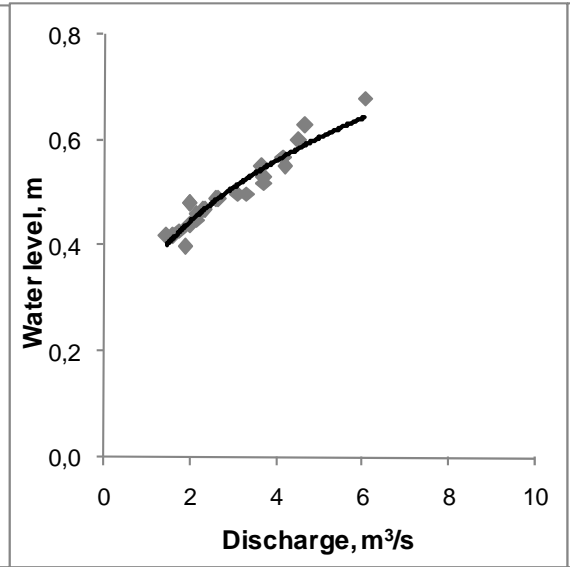

(b)

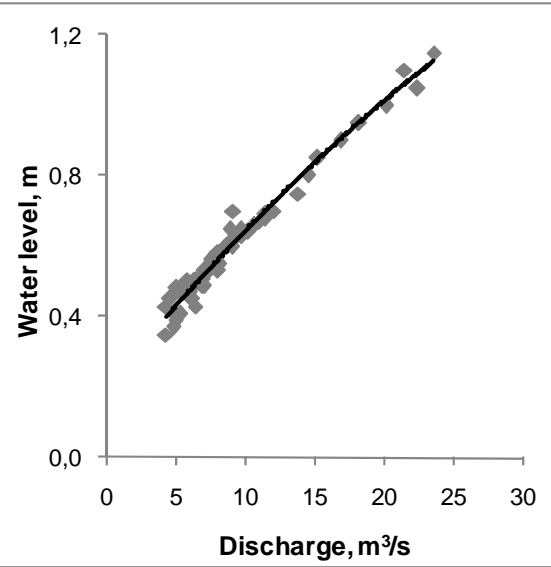

(c)

Figure 2. Rating curves for (a) Way Simpur; (b) Way Awi; and (c) Way Kuala Garuntang.

\begin{tabular}{|c|c|c|c|c|c|c|c|}
\hline No. & Date & $\begin{array}{l}\text { Peak Discharge } \\
\left(\mathrm{m}^{3} / \mathrm{sec}\right)\end{array}$ & $\begin{array}{l}\text { Rainfall Depth } \\
\text { (mm) }\end{array}$ & $\begin{array}{l}\text { Rainfall Duration } \\
\text { (hours) }\end{array}$ & $\begin{array}{c}\phi_{\text {index }} \text { Time step } \\
1 \mathrm{hr}\end{array}$ & $\begin{array}{c}\phi_{\text {index }} \text { Time step } \\
30 \mathrm{~min}\end{array}$ & $\begin{array}{c}\phi_{\text {index }} \text { Time step } \\
10 \mathrm{~min}\end{array}$ \\
\hline 1 & $16-01-2010$ & 3.453 & 8 & 1 & 7.617 & 6.012 & 5.544 \\
\hline 2 & $17-01-2010$ & 6.437 & 6 & 1 & 5.225 & 2.908 & - \\
\hline 3 & $17-01-2010$ & 4.050 & 5.6 & 1 & 4.511 & 3.024 & 2.591 \\
\hline 4 & $31-01-2010$ & 3.769 & 10.8 & 2 & 9.273 & 4.044 & 2.006 \\
\hline 5 & 01-02-2010 & 20.015 & 22.2 & 2 & 7.622 & - & - \\
\hline 6 & 04-02-2010 & 2.705 & 7.2 & 1 & 4.676 & 2.768 & - \\
\hline 7 & 06-02-2010 & 1.339 & 2.8 & 1 & 2.554 & 1.854 & 0.757 \\
\hline
\end{tabular}

Table 1. Flood events selected for Way Simpur catchment. 
Table 2. Flood events selected for Way Awi catchment.

\begin{tabular}{|c|c|c|c|c|c|c|c|}
\hline No. & Date & $\begin{array}{c}\text { Peak Discharge } \\
\left(\mathrm{m}^{3} / \mathrm{sec}\right)\end{array}$ & $\begin{array}{l}\text { Rainfall Depth } \\
\text { (mm) }\end{array}$ & $\begin{array}{l}\text { Rainfall Duration } \\
\text { (hours) }\end{array}$ & $\begin{array}{c}\phi_{\text {index }} \text { Time step } \\
1 \mathrm{hr}\end{array}$ & $\begin{array}{c}\phi_{\text {index }} \text { Time step } \\
30 \mathrm{~min}\end{array}$ & $\begin{array}{c}\phi_{\text {index }} \text { Time step } \\
10 \mathrm{~min}\end{array}$ \\
\hline 1 & 08-01-2010 & 21.693 & 7.4 & 1 & 6.346 & 4.025 & 2.517 \\
\hline 2 & 16-01-2010 & 17.354 & 7 & 1 & 5.640 & 3.038 & 3.147 \\
\hline 3 & 17-01-2010 & 19.043 & 6.2 & 1 & 2.589 & 5.251 & 4.364 \\
\hline 4 & $12-02-2010$ & 14.426 & 8.6 & 2 & 6.170 & 4.965 & 2.868 \\
\hline
\end{tabular}

Table 3. Flood events selected for Way Kuala Garuntang catchment.

\begin{tabular}{|c|c|c|c|c|c|c|c|}
\hline No. & Date & $\begin{array}{c}\text { Peak Discharge } \\
\left(\mathrm{m}^{3} / \mathrm{sec}\right)\end{array}$ & $\begin{array}{l}\text { Rainfall Depth } \\
\text { (mm) }\end{array}$ & $\begin{array}{l}\text { Rainfall Duration } \\
\text { (hours) }\end{array}$ & $\begin{array}{c}\phi_{\text {index }} \text { Time step } \\
1 \mathrm{hr} \\
\end{array}$ & $\begin{array}{c}\phi_{\text {index }} \text { Time step } \\
30 \mathrm{~min}\end{array}$ & $\begin{array}{c}\phi_{\text {index }} \text { Time step } \\
10 \mathrm{~min}\end{array}$ \\
\hline 1 & 25-12-2009 & 12.770 & 28.4 & 1 & 26.746 & 25.734 & 16.044 \\
\hline 2 & 28-12-2009 & 31.426 & 10.2 & 1 & 5.315 & 3.717 & 1.259 \\
\hline 3 & $31-12-2009$ & 9.413 & 9.4 & 1 & 8.484 & 8.347 & 4.541 \\
\hline 4 & 08-01-2010 & 14.111 & 7.4 & 1 & 5.826 & 1.790 & 4.506 \\
\hline 5 & $10-01-2010$ & 26.606 & 31.6 & 4 & 10.076 & - & - \\
\hline 6 & 13-01-2010 & 9.413 & 8.6 & 2 & 3.372 & 2.381 & 0.982 \\
\hline 7 & $14-01-2010$ & 19.509 & 5.8 & 1 & 3.184 & 2.44 & - \\
\hline 8 & 16-01-2010 & 21.089 & 8 & 1 & 4.744 & 3.406 & 3.320 \\
\hline 9 & 20-01-2010 & 19.234 & 8.2 & 1 & 5.516 & 5.646 & 2.216 \\
\hline 10 & 27-01-2010 & 48.232 & 44.6 & 2 & 35.135 & 25.128 & 11.431 \\
\hline 11 & 28-01-2010 & 15.205 & 19.6 & 1 & 18.054 & 18.053 & 12.834 \\
\hline 12 & 01-02-2010 & 38.442 & 22.2 & 2 & 18.337 & 10.393 & - \\
\hline 13 & 04-02-2010 & 23.164 & 7.2 & 1 & 3.935 & 1.832 & 0.700 \\
\hline 14 & 05-02-2010 & 47.388 & 14 & 3 & 5.594 & 2.351 & - \\
\hline 15 & 08-03-2010 & 28.895 & 15.8 & 1 & 13.869 & 6.698 & - \\
\hline 16 & $10-03-2010$ & 30.537 & 18.8 & 2 & 7.031 & - & - \\
\hline 17 & 13-03-2010 & 11.889 & 5.6 & 1 & 3.071 & 2.253 & 1.792 \\
\hline
\end{tabular}

step, i.e. less than 1 hour. In this study time steps of 10 , 30 and 60 minutes are used as presented in Tables 1-3 and Figures 4-6.

Calculated $\phi_{\text {index }}$ for each event and time step are presented in the last three columns of Tables 1-3. The first event which is in December 25, 2009 shows large value of $\phi_{\text {index }}$, which can be understood as a lot of portion of rains were infiltrated. The value of $\phi_{\text {index }}$ decreases for the next few events, but increases considerably for these subsequent events of 27-01-2010, 28-01-2010 and 1-022010 and again on 8-03-2010. Therefore, it cannot be concluded that the value of $\phi_{\text {index }}$ will decrease toward the peak of wet season (i.e. in January-March). In fact, the value of $\phi_{\text {index }}$ is defined in such a way that the computed series of excess precipitation suitable with the observed discharge. In contrast to the absence of trend of $\phi_{\text {index }}$ values in the flood events, the value of $\phi_{\text {index }}$ tends to decrease for smaller time step.

The results presented in Tables 1-3 and Figures 4-6 show that not all events which can be used to develop unit hydrographs for a certain time step can be used to develop those for smaller time steps. This may happen as the within storm rainfall pattern (distribution of rainfall depth for each time step) is more detail for smaller time step, so that for particular rainfall is not possible to get the $\phi_{\text {index }}$ and volume of effective rainfall which fit runoff volume. This may also due to the selected method for calculating effective rainfall which uses a linear approach rather than non-linear approach such as Green-Apmt or other methods. 

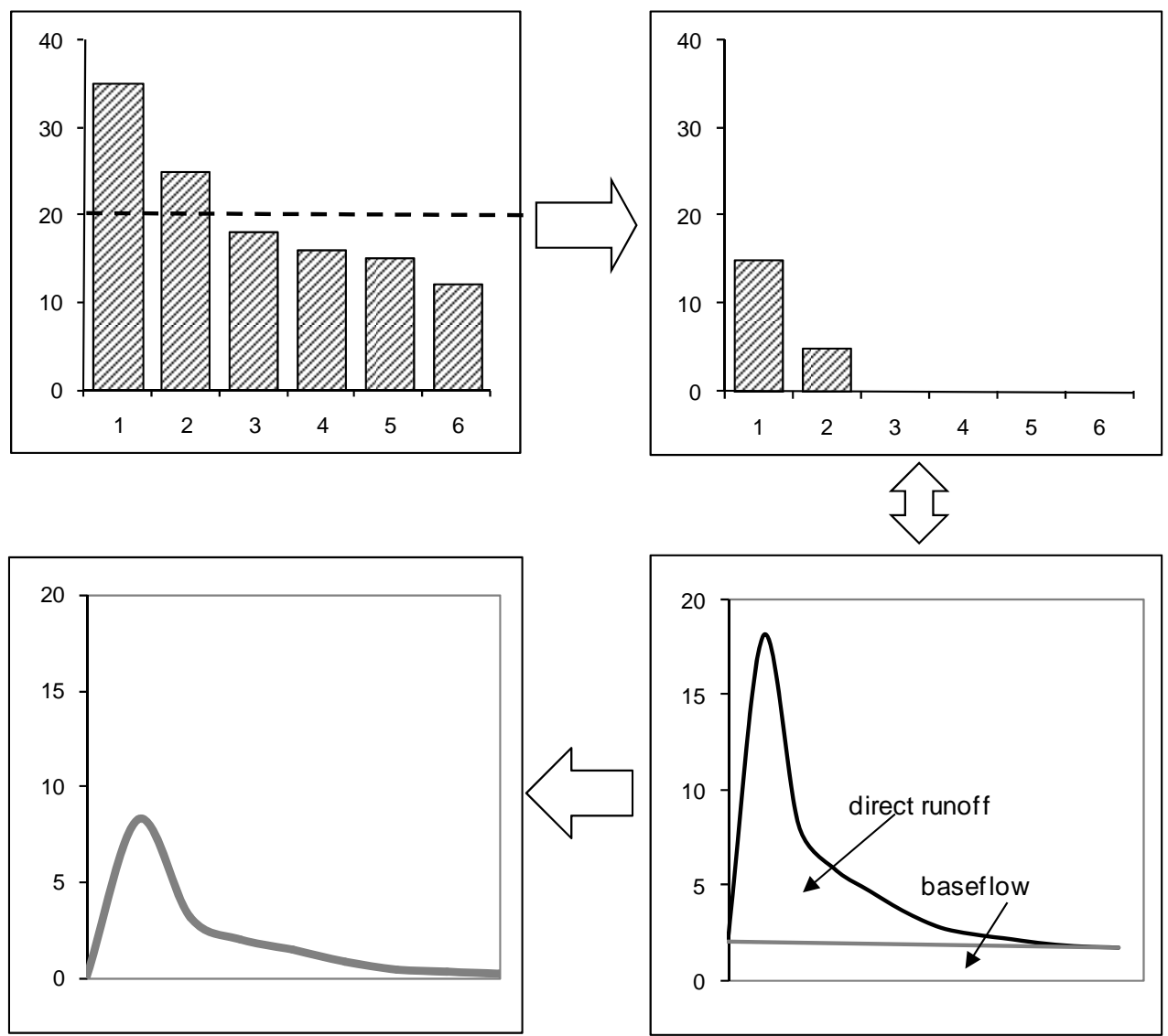

Figure 3. Effective rainfall, baseflow separation and unit hydrograph.

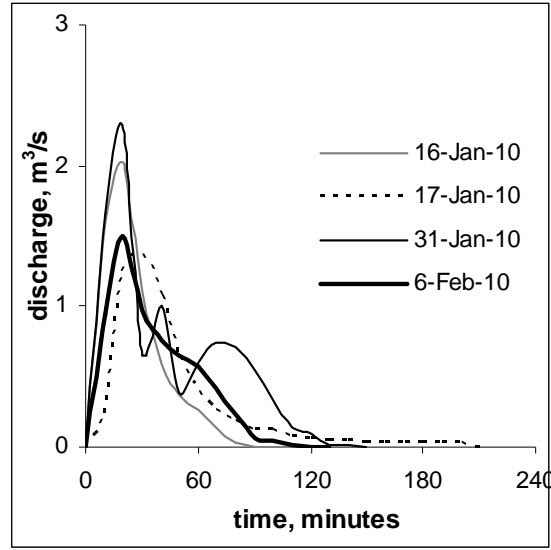

(a)

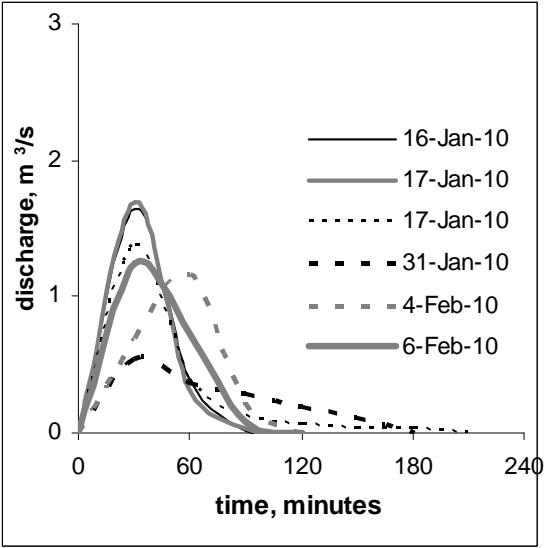

(b)

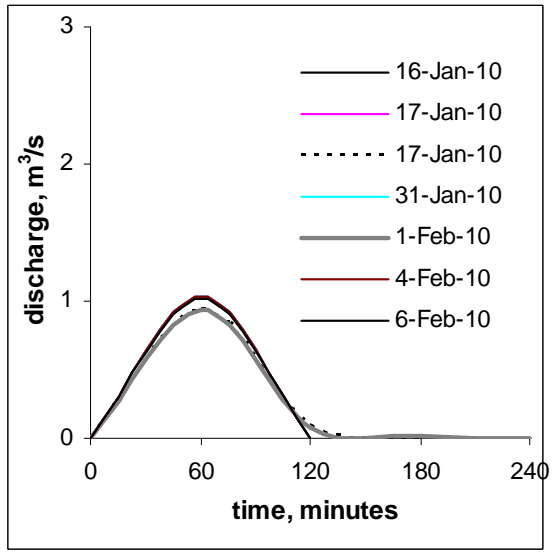

(c)

Figure 4. Observed unit hydrographs for Way Simpur using time steps (a) 10; (b) 30; and (c) 60 minutes.

\subsection{Time Steps and Time to Peak}

The unit hydrographs developed are presented in Figures 4-6, where Figures 4-6 show unit hydrographs of Way Simpur, Way Awi and Way Kuala Garuntang respectively. For each catchment, the unit hydrograph is developed for time step 10, 30 and 60 minutes. The advantage of using small time step is to gain an understanding about the real time to peak for the catchment. For the case of Way Simpur (Figure 4), using time step of 10 minutes it can show that the average time to peak in that catchment is 20 minutes. While using time step of 30 and 60 minutes show that the averages of time to peak are 30 and 60 minutes respectively. Among those three time steps, it seems that time to peak resulted from time step of 10 minutes is the most reasonable as the catchment is 


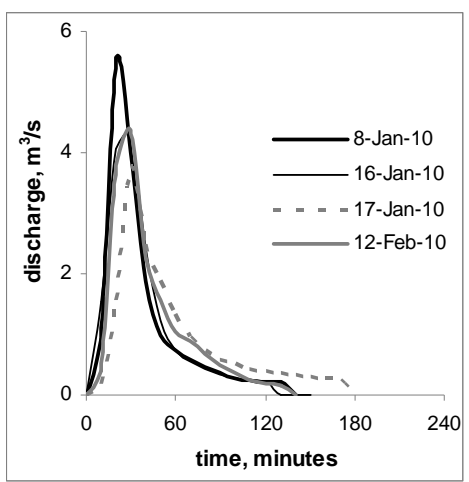

(a)

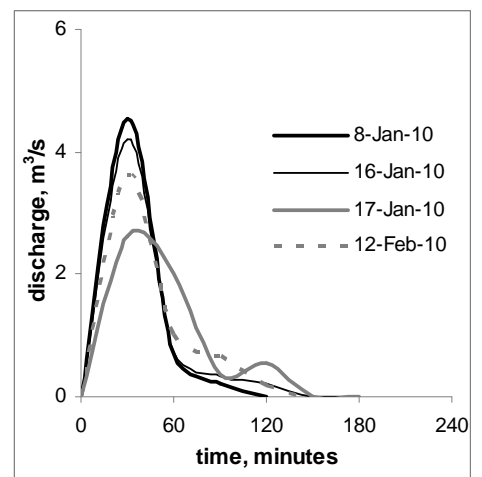

(b)

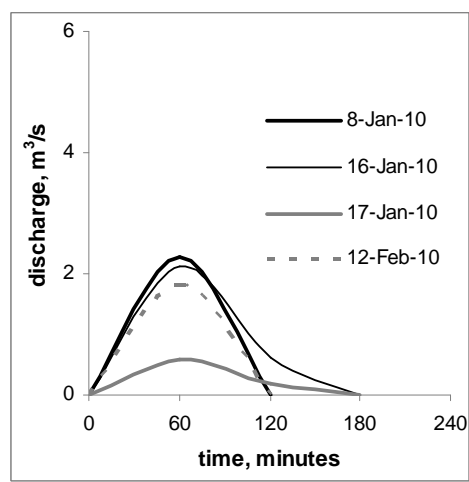

(c)

Figure 5. Observed unit hydrographs for Way Awi using time steps (a) 10; (b) 30; and (c) 60 minutes.
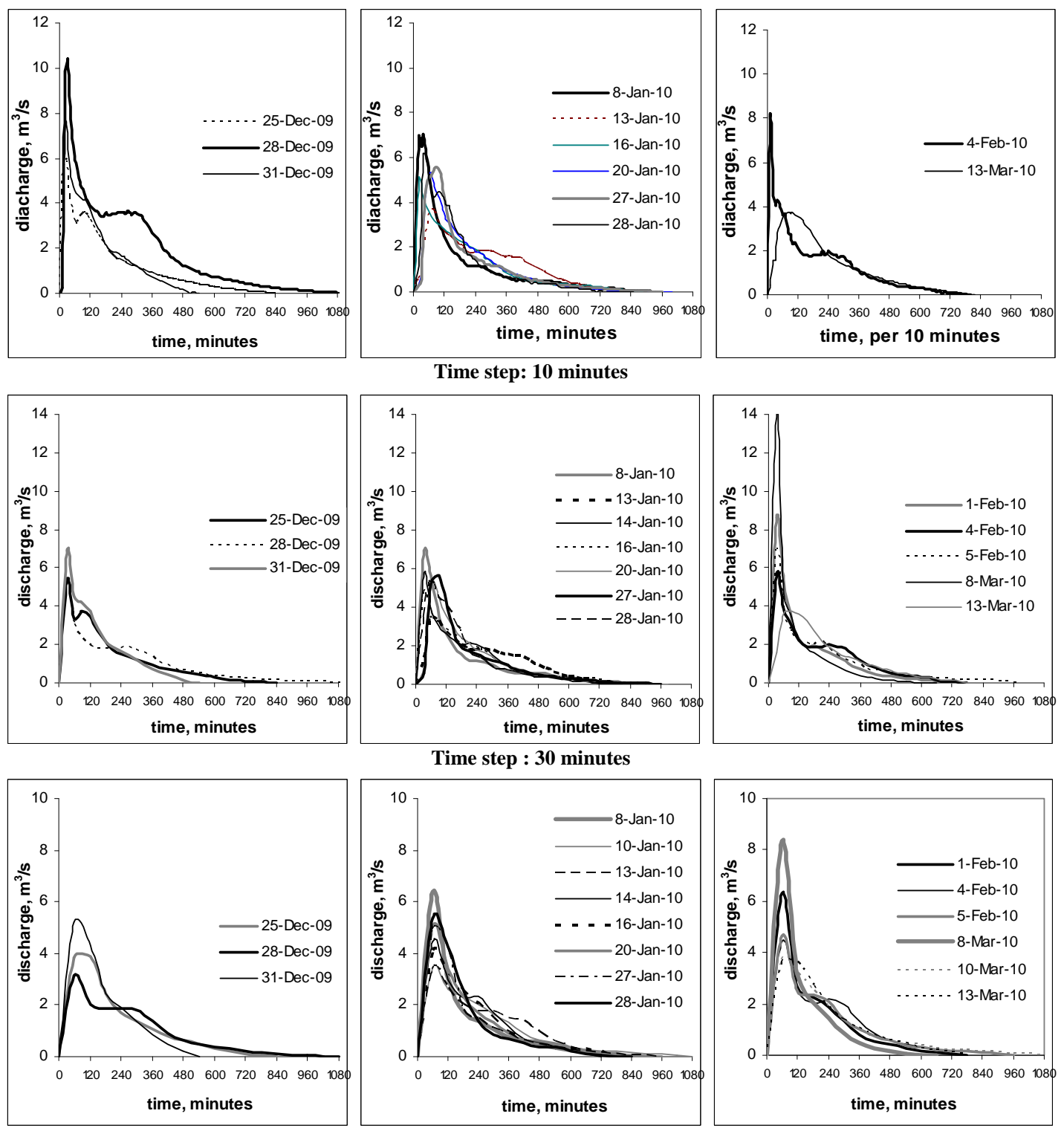

Time step : 1 hour

Figure 6. Observed unit hydrographs for Way Kuala Garuntang according to the months using time steps 10, 30 and 60 minutes. 
considered small.

For Way Awi (Figure 5), using different time steps also show different results for time to peak. Using time step of 10,30 and 60 minutes resulted in average time to peak of 30, 30 and 60 minutes respectively. Again, smaller time step gives more reasonable results in indicating time to peak.

For Way Kuala Garuntang, in addition to time step, the unit hydrographs are also made into three groups according to the months. The groups are for December, January, as well as February and March events (Figure 6). The average time to peak for time step of 10 minutes is 30, 60 and 60 minutes for December, January and February-March events respectively. While the average time to peak for time steps of 10 minutes for overall events is 60 minutes. For time step of 30 minutes, the average time to peak is $30,60,60$ and 60 minutes for December, January, February-March and overall events respectively. The average time to peak for time step of 60 minutes is 60 minutes for December, January, FebruaryMarch and overall events. For a larger catchment such as Way Kuala Garuntang, smaller time steps confirm time to peak as resulted from larger time step. In this case, it is predicted that the appropriate time to peak for Way Kuala Garuntang is 60 minutes.

\subsection{Time Steps and Peak Discharges}

In addition to time to peak, another important issue with regard to unit hydrograph is the peak discharge. For Way Simpur (Figure 4) peak discharges for all time steps are in the range of $0.5-2.4 \mathrm{~m}^{3} / \mathrm{s}$, where the average peak discharges for time steps 10,30 and 60 minutes are 1.8 $\mathrm{m}^{3} / \mathrm{s}, 1.2 \mathrm{~m}^{3} / \mathrm{s}$ and $1 \mathrm{~m}^{3} / \mathrm{s}$ respectively. Please note that in fact there are seven peak discharges in the unit hydrographs for Way Simpur using time step 60 minutes (Figure 4(c)), which seems to be sorted into two groups because five of them are in the range of $1.023-1.028 \mathrm{~m}^{3} / \mathrm{s}$ and the other two are 0.931 and $0.937 \mathrm{~m}^{3} / \mathrm{s}$. Therefore it looks like there are only two curves as the outcome of seven flood events (Figure 4(c)).

For Way Awi (Figure 5) the average peak discharges for time steps 10,30 and 60 minutes are $4.1 \mathrm{~m}^{3} / \mathrm{s}, 3.7$ $\mathrm{m}^{3} / \mathrm{s}$ and $1.8 \mathrm{~m}^{3} / \mathrm{s}$ respectively. The results show the smaller the time step the larger the peak discharge. This happen because only selected flood events which have high rainfall intensity during short time interval are able to be utilized in constructing unit hydrograph. Therefore, the rainfall intensity is larger at smaller time step which impacts on larger peak discharge.

The average peak discharges for Way Kuala Garuntang for December, January and February-March events (Figure 6) using time step 10 minutes are $7.7 \mathrm{~m}^{3} / \mathrm{s}, 4.5$ $\mathrm{m}^{3} / \mathrm{s}$ and $4.2 \mathrm{~m}^{3} / \mathrm{s}$ respectively, using time step $30 \mathrm{~min}$ - utes are $5.8 \mathrm{~m}^{3} / \mathrm{s}, 4.7 \mathrm{~m}^{3} / \mathrm{s}$ and $7.4 \mathrm{~m}^{3} / \mathrm{s}$ respectively and using time step 60 minutes are $4 \mathrm{~m}^{3} / \mathrm{s}, 4.6 \mathrm{~m}^{3} / \mathrm{s}$ and 5.2 $\mathrm{m}^{3} / \mathrm{s}$ respectively. While the trend of average peak discharges seem opposite for time step 10 minutes, the trend of those for other time steps shows there is an increase of average peak discharges toward the peak of wet season. For February-March flood events there were only two out of six flood events which were able to be utilized in unit hydrograph using time step 10 minutes, and there were only six out of eight events for January flood events could be utilized for 10 minute time step hydrograph. Meanwhile, all three flood events in December could be used for 10 minute time step hydrograph. Therefore the results from using time step 10 minutes show inconsistent trend with regard to the wetter season as the lack of data.

\subsection{The Average of Unit Hydrographs for Different Time Steps}

Comparing the results between those three catchments there is a general trend of average peak discharge, i.e. the higher the time step, the lower the average peak discharge (Figure 7). This trend does not fully work for Way Garuntang as the peak discharge using time step 10 minutes is lower compare to that using time step 30 and 60 minutes. Considering overall events for Way Kuala Garuntang, average peak discharges for time steps 10, 30 and 60 minutes are $4.64 \mathrm{~m}^{3} / \mathrm{s}, 5.2 \mathrm{~m}^{3} / \mathrm{s}$ and $4.7 \mathrm{~m}^{3} / \mathrm{s}$. Although in nearly all unit hydrographs, peak discharges resulted from using time step 10 minutes are larger compared to peak discharges resulted from using larger time step. This may happen because the method in calculating the average peak discharge is so simple, that is simply taking the average of the events for particular time step, both for the discharge and time to peak. Furthermore, peak discharge is closely related to time to peak. Using small time step, time to peak may vary significantly between 10 to 60 minutes. Considering peak discharges which occur at various time to peak, this may result in low average of peak discharge as in the case of average peak discharge of Way Kuala Garuntang using time step 10 minutes.

\section{Conclusions}

This study shows the impact of time steps on unit hydrographs with regard to time to peaks and peak discharges. In general, smaller time step gives more accurate resulted unit hydrographs. It was observed that the average time to peaks for Way Simpur are 20, 30 and 60 minutes using time steps 10, 30 and 60 minutes respectively. The average time to peaks for Way Awi are 30, 30 and 60 minutes using time steps 10, 30 and 60 minutes respectively. And the average time to peaks for Way Kuala Garuntang are 


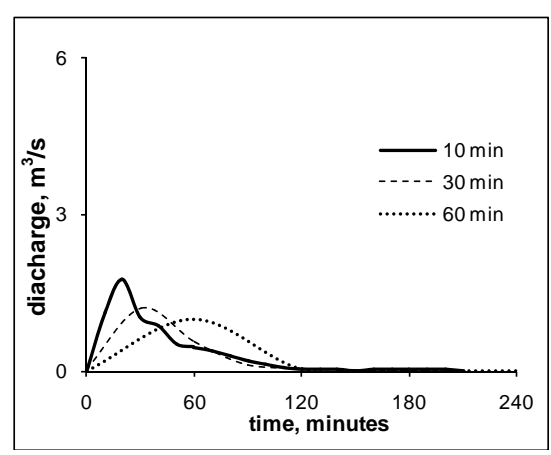

(a)

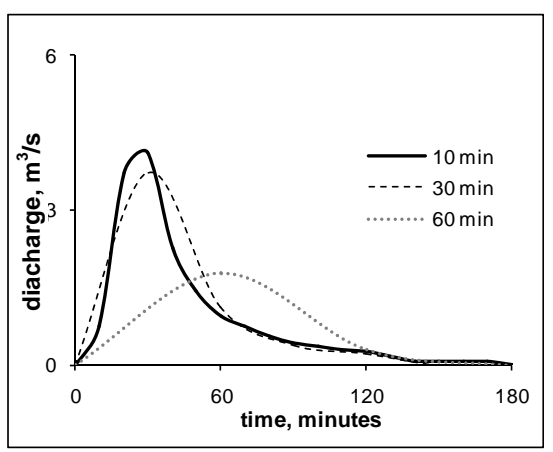

(b)

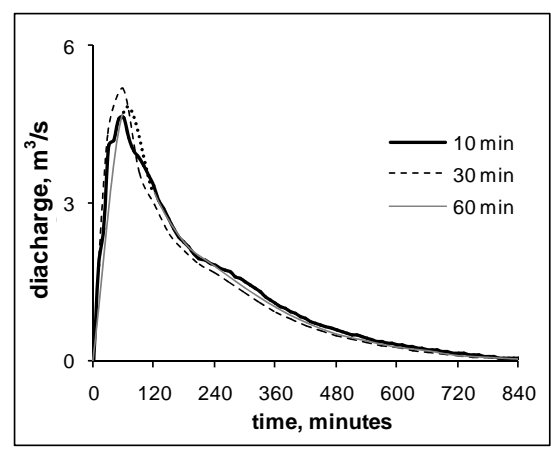

(c)

Figure 7. Average of unit hydrographs for time steps 10, 30 and 60 minutes for catchments (a) Way Simpur; (b) Way Awi; and (c) Way Garuntang.

60, 60 and 60 minutes using time steps 10, 30 and 60 minutes respectively.

Time steps used in determining unit hydrographs may produce different peak discharges. The results show that the trend of peak discharges increases by using smaller time step. However, the average peak discharge provided by using time step 10 minutes for Way Kuala Garuntang does not correspond with the trend. For several flood events used in determining unit hydrographs, the time to peaks and corresponding peak discharges using time step 10 minutes vary considerably. Therefore the averaging of those variables causes the average value of peak discharge is not maximum.

In addition to that, the resulted unit hydrographs also show that the trend of peak discharges increases toward wetter months during the wet season. However, the peak discharges resulted from using time step 10 minutes do not show this trend due to limited number of flood events which could be used to calculate the unit hydrograph using such small time step.

\section{Acknowledgements}

This study was supported by National Strategic Research Funding 2009 and 2012 under Department of Research and Community Service, Department of Higher Education Indonesia (DIKTI).

\section{REFERENCES}

[1] M. Sivapalan, J. Schaake and J. Sapporo, "PUB Science and Implementation Plan V5,” 2003.

http://pub.iwmi.org/UI/Images/PUB_Science_Plan_V_5. pdf

[2] M. Sivapalan, K. Takeuchi, S. Franks, V. K. Gupta, H. Karambiri, V. Lakshmi, X. Liang, J. McDonnell, E.
Mendiondo, E. P. O’Connell, T. Oki, J. W. Pomeroy, D. Schertzer, S. Uhlenbrook and E. Zehe, "IAHS Decade on Predictions in Ungauged Basins (PUB), 2003-2012: Shaping an Exciting Future for the Hydrologic Sciences," Hydrological Sciences Journal, Vol. 48, No. 6, 2003, pp. 857-880. doi:10.1623/hysj.48.6.857.51421

[3] D. I. Kusumastuti, "The Impact of Rainfall Variability and Hydrological Regimes on Flood Frequency,” Proceedings International Seminar on Water Related Risk Management, Jakarta, 15-17 July 2011, pp. 131-136.

[4] J. Seibert and K. Beven, "Gauging the Ungauged Basin: How Many Discharge Measurements are Needed?” Hydrology and Earth System Sciences, Vol. 13, 2009, pp. 883-892. doi:10.5194/hess-13-883-2009

[5] D. Duband, Ch. Oblend and J. Y. Rodriguez, “Unit Hydrograph Revisited: An Alternate Iterative Approach to UH and Effective Precipitation Identification,” Journal of Hydrology, Vol. 150, No. 1, 1993, pp. 115-149. doi:10.1016/0022-1694(93)90158-6

[6] D. K. Natakusumah, D. Harlan and W. Hatmoko, “A General Procedure for Development of ITB-1 and ITB-2 Synthetic Unit Hydrograph Based on Mass Conservative Principle,” Proceedings International Seminar on Water Related Risk Management, Jakarta, 15-17 July 2011, pp. 114-122.

[7] B. Sri Harto, "Study of the Unit Hydrograph Basic Characteristics of Rivers on the Island of Jawa for Flood Estimation,” Doctoral Thesis, Gadjah Mada University, Jakarta, 1985.

[8] A. B. Safarina, "Reliability of Nakayasu Synthetic Unit Hydrograph in Various Watershed Area," Proceedings International Seminar on Water Related Risk Management, Jakarta, 15-17 July 2011, pp. 123-130.

[9] S. K. Jena and K. N. Tiwari, "Modeling Synthetic Unit Hydrograph Parameters with Geomorphologic Parameters of Watersheds,” Journal of Hydrology, Vol. 319, No. 1-4, 2006, pp. 1-14. doi:10.1016/j.jhydrol.2005.03.025 